\title{
A CULTURA DA LIBERDADE DE CRIAÇÃO E 0 CERCEAMENTO TECNOLÓGICO E NORMATIVO: POTENCIALIDADES PARA A AUTORIA NA EDUCAÇÃO
}

\author{
THE CULTURE OF THE FREEDOM OF CREATION AND \\ TECHNOLOGICAL AND REGULATORY RESTRICTIONS: \\ POTENTIAL FOR AUTHORING IN EDUCATION
}

\author{
LA CULTURA DE LA LIBERTAD DE CREACIÓN Y EL \\ CERCENAMIENTO TECNOLÓGICO Y NORMATIVO: LAS \\ POTENCIALIDADES PARA LA AUTORÍA EN EDUCACIÓN
}

\section{Maristela Midlej Silva de Araújo Veloso ${ }^{1}$ Maria Helena Silveira Bonilla ${ }^{2}$ Nelson De Luca Pretto ${ }^{3}$}

\begin{abstract}
RESUMO: O texto discute os processos que se articulam em torno do acesso ao conhecimento e à infraestrutura básica comum, a qual envolve toda a cadeia da produção de bens imateriais, formada por três camadas: a física, a lógica e a de conteúdo. Considera que as tecnologias digitais e a abundância de informações disponíveis no ciberespaço vêm, cada vez mais, ampliando as possibilidades de autoria dos professores e dos alunos no cotidiano escolar (do Ensino Fundamental à universidade). No entanto, sem aqueles elementos (acesso comum e infraestrutura) que são indispensáveis para a implantação na educação da autoria, ela não se viabilizaria. Assim, considera que a produção de conteúdo no contexto da cibercultura está condicionada pela infraestrutura tecnológica e pelos usos, trocas e meios de criação de conhecimentos. Por fim, a partir do referencial teórico sobre a temática em questão e de vivências em contextos escolares e universitários, conclui-se que a cultura da construção coletiva e colaborativa em rede de textos, imagens e sons só poderá ser concretizada se for permitido a todos o direito e a liberdade de usufruir dos bens imateriais produzidos pela humanidade.
\end{abstract}

PALAVRAS-CHAVE: Tecnologias digitais. Cerceamento tecnológico e normativo. Cultura da liberdade. Autoria e educação. Direito Autoral.

\begin{abstract}
The paper discusses the processes that hinge around access to knowledge and common basic infrastructure, which involve the whole chain of production of such goods. There are three layers: the physical, logic and content layer. It is thought that digital technology and the abundance of information available in cyberspace are increasingly expanding authoring possibilities for teachers and students in schools (elementary to higher education). However, without common access and infrastructure, which indispensable for the implementation of authorship in education, this is impossible. We consider that the production of content in the context of cyberculture is conditioned by the technological infrastructure and the use, exchange and means of knowledge creation. Finally, from the theoretical framework used in our approach and based on our investigations and experiences in schools and at the university, we
\end{abstract}

\footnotetext{
${ }^{1}$ Doutora em Educação pela Universidade Federal da Bahia, UFBA, Brasil. Professora do Instituto de Humanidades, Artes e Ciências da Universidade Federal do Sul da Bahia, UFSB, Itabuna, BA, Brasil. E-mail: marimidlej@ gmail.com.

${ }^{2}$ Doutora em Educação pela Universidade Federal da Bahia, UFBA, Brasil. Professora associada do Departamento de Educação, Universidade Federal da Bahia, UFBA, Salvador, BA, Brasil. E-mail: bonillabr@gmail.com.

${ }^{3}$ Doutor em Ciências da Comunicação pela Universidade de São Paulo, USP, Brasil. Professor do Departamento de Educação da Universidade Federal da Bahia, UFBA, Salvador, BA, Brasil. E-mail: nelson@pretto.pro.br.
}

Recebido em: 11/08/2015 - Aprovado em: 03/12/2015. 
conclude that the culture of collective and collaborative production of texts, images and sounds can only be achieved if the right and the freedom to experience the intangible assets produced by mankind are available and accessible to everyone.

KEYWORDS: Digital technologies; Technological and regulatory restriction. Culture of freedom. Authorship and education. Copyright.

RESUMEN: El texto analiza los procesos que se articulan en torno de el acceso al conocimiento y la infraestructura básica común, que involucra a toda la cadena de producción de bienes intangibles, formado por tres estratos: el físico, el lógico y el de contenido. Considera que la tecnología digital y la abundancia de la información disponible en el ciberespacio vienen, cada vez más, aumentando las posibilidades de creación de profesores y estudiantes en el cotidiano escolar (de la escuela primaria hasta la universidad). Sin embargo, sin esos elementos (acceso común y infraestructura) que son indispensables para la implantación en la educación de la autoría, ella no es posible. De esta manera, considera que la producción de contenidos en el contexto de la cibercultura está condicionada por la infraestructura tecnológica y el uso, intercambio y medios de creación de conocimientos. Por último, desde el marco teórico sobre el tema en cuestión y vivencias en el ámbito escolar y universitario, se concluye que la cultura de construcción colectiva y colaborativa en la red de textos, imágenes y sonidos sólo se puede lograr si se permite en absoluto el derecho y la libertad para usufructuar de los bienes intangibles producidos por la humanidad.

PALABRAS CLAVE: Tecnologías digitales. Cercenamiento tecnológico y normativo. Cultura de la libertad. Autoría y educación. Direito Autoral.

\section{INTRODUÇÃO}

As redes de comunicação digital trazem para a educação enormes possibilidades, ao mesmo tempo que introduzem enormes desafios. Passamos de uma era na qual as informações eram escassas e de difícil acesso para um momento em que abundam informações, imagens e sons. Tratar desse universo comunicacional na escola é tarefa urgente, uma vez que as possibilidades são amplas, permitem que os processos educativos estejam centrados na autoria e fazem com que a escola seja produtora de conhecimentos e de culturas.

No entanto, a autoria de professores e alunos, no cotidiano escolar - do Ensino Fundamental à universidade -, no contexto da cibercultura, está condicionada pela infraestrutura tecnológica e pelos usos, trocas e processos de criação de conhecimentos. A cultura da construção coletiva e colaborativa de conhecimentos em rede só poderá ser materializada se for permitido a todos o direito e a liberdade de usufruir dos bens imateriais produzidos pela humanidade.

Diante disso, o presente texto tem como objetivo discutir sobre os processos que se articulam em torno do acesso ao conhecimento e à infraestrutura básica comum, bases necessárias para a autoria no cotidiano escolar. O acesso ao conhecimento demanda, antes de tudo, como nos mostra Yochai Benkler (2007), essa infraestrutura básica comum, a qual envolve toda a cadeia da produção desses bens, formada por três camadas: a física, a lógica e a de conteúdo. A camada física, que trata como os bits são transformados em sinais eletromagnéticos e transportados por conectores, cabos e fibras, é onde se encontra a propriedade dos fios e das licenças de transmissão por ondas, necessárias à comunicação. Aqui, o foco da nossa discussão será a conectividade, no tocante à banda larga nas escolas. A camada lógica é constituída pelos padrões, protocolos e softwares. Para o interesse deste texto, a discussão estará no confronto softwares livres/proprietários, além dos formatos abertos/fechados. Por fim, na camada de conteúdo, estão as questões relacionadas à propriedade 
intelectual e aos modelos de negócios, quando será dado enfoque à discussão relacionada aos direitos de usos do conhecimento e dos bens culturais, no tocante às amarras da atual Lei dos Direitos Autorais, em contraponto com a cultura livre. Essa infraestrutura básica, formada pelas três camadas, precisa de um fundamento que potencialize a liberdade de criação - e esse fundamento está nas possibilidades de abertura dos processos, ou seja, nos commons e no direito à criação de cultura e conhecimento.

\section{AS POTENCIALIDADES DOS COMMONS}

A lógica da criação dos commons deve ser entendida como uma forma de garantir o direito à cultura, tendo como objetivo a promoção de uma sociedade fundamentada no diálogo, em oposição ao processo de "privatização" do saber e concentração da riqueza que acirram as atitudes focadas na exclusão e que impedem o acesso às fontes de cultura.

Os commons podem ser definidos como "um tipo particular de arranjo institucional que governa o uso e a disposição de recursos. [...] A característica, que os define de forma distinta da propriedade ${ }^{\mathrm{i}}$, é que nenhuma pessoa tem o controle exclusivo do uso e da disposição de qualquer recurso particular". (BENKLER, 2007, p. 12). Para o autor, podemos dividir os commons em quatro tipos, a partir de dois parâmetros. Quanto à abertura, eles podem ser abertos a todos, ou abertos a poucos; quanto à regulação, eles podem ser regulados ou não regulados.

No primeiro parâmetro, o autor cita os oceanos, o ar que respiramos e os sistemas rodoviários como commons abertos a todos, considerados como de interesse público. Por outro lado, a depender das restrições no uso e na disposição, alguns são limitados a membros de um grupo, como no caso da propriedade do tipo tradicional, a exemplo de certos tipos de pastos ou sistemas de irrigação. Em relação ao segundo parâmetro, Benkler afirma que quase todos os regimes de propriedade comum são limitados por regras, que podem ser mais ou menos elaboradas, sendo algumas mais formais e outras construídas socialmente. Assim, os commons abertos são variados, alguns deles não governados por alguma regra - os de acesso aberto. $\mathrm{O}$ ar, por exemplo, qualquer um pode usá-lo, seja para a respiração ou para o funcionamento de uma turbina, sem nenhum tipo de pagamento. Por outro lado, mesmo para o ar, há regras, sejam por "convenções sociais" - "não respiramos diretamente no rosto de outra pessoa, a menos que a isto sejamos forçados" (p. 13) - ou por regras mais formalizadas, como, por exemplo, no controle da poluição das instalações industriais.

Benkler (2007, p. 13), com essa divisão/categorização dos tipos de commons, busca destacar que o conhecimento é o "recurso mais importante que governamos como commons aberto" uma vez que, sem ele, "a humanidade não poderia ser concebida", já que fazem parte desse conjunto "todo conhecimento anterior ao século XX, a maior parte do conhecimento científico da primeira metade do século XX e grande parte da ciência e do conhecimento acadêmico contemporâneos" (p. 13-14). Cintia Beatriz Martins (2012) enfatiza que, para fazer uma análise sobre o conhecimento e a cultura como commons, existe uma característica desse tipo de recurso que deve ser destacada - a natureza não rival e não exclusiva dos bens imateriais. Esse é um aspecto significativo que diferencia o capitalismo fordista, próprio da sociedade industrial, baseado na produção de bens materiais, para o 
cognitivo, constituído a partir da manipulação dos bens simbólicos imateriais, inerente da sociedade em rede.

O termo rival é originado da economia e corresponde ao bem, ou recurso, cujo uso impede o uso simultâneo por outra pessoa, ou compete com a sua utilização. Um bem ou recurso não rival é o que admite usos concomitantemente. Para avançar na discussão sobre o significado de um bem rival ou não rival, Imre Simon e Miguel Said Vieira (2008) resgatam uma palavra portuguesa pouco usada - rossio -, apesar de ela ter o mesmo significado de commons, como argumentam no texto $O$ rossio não rival. Portanto, na definição dos autores, o rossio (ou commons) é "um conjunto de recursos utilizados em comum e equitativamente por uma determinada comunidade. Não existem direitos individuais de exclusão no rossio" (p. 16). Ou seja, um rossio não rival é aquele que o seu uso por um não impede o uso por outros, podendo ser usado em comum por uma ou várias comunidades. Os autores ainda ressaltam que o rossio rival é caracterizado pela escassez, e o rossio não rival se caracteriza (ao menos potencialmente) pela abundância. Dessa forma, "os bens intangíveis - como as ideias, os programas de computador, as obras artísticas, científicas e culturais - são em geral, não rivais" (p. 17). Assim, esses bens, no passado, só poderiam ser armazenados em nossas memórias ou em estruturas como a de uma biblioteca física, ficando presos a suportes físicos que os tornavam bens rivais, como os exemplares de livros. Com as potencialidades da tecnologia digital, todos esses bens tornaram-se rossios não rivais, mais amplos e mais baratos, com um grande potencial de circulação, trazendo para a cena contemporânea as possibilidades da produção social realizada em rede. É importante considerar os bens imateriais como commons porque possibilitam "um ambiente em que os indivíduos e grupos são capazes de produzir informação e cultura por conta própria" (BENKLER, 2007, p. 16), tornando-os não escassos. Isso, mesmo que considerado apenas potencialmente, em função das precárias condições concretas de infraestrutura tecnológica, como as que temos nas escolas brasileiras, contribui para a disseminação de conhecimentos, sem cessar, incentivando a criatividade e, o mais importante, o permanente reuso e a remixagem desses conhecimentos.

Evidentemente, com a expansão e o compartilhamento do conhecimento e da produção cultural na rede, não é só a figura do indivíduo autor que tem sido abalada, mas toda a cadeia de criação e difusão das obras intelectuais. Sergio Amadeu da Silveira (2007) chama a atenção que, nesse contexto, emergem dois componentes antagônicos, simultâneos, que expressam valores e objetivos distintos, os quais influenciam no funcionamento dessa infraestrutura. $\mathrm{O}$ autor alerta que, de um lado, há um grupo que "quer aprofundar a liberdade de fluxos e a produção do comum, ou seja, ampliar os espaços públicos, a liberdade e o domínio público, seja no uso seja na evolução tecnológica da rede" (p. 26). Mas, de outro lado, há um grupo que quer "contê-la em um processo econômico baseado na apropriação privada do conhecimento, dos bens imateriais e dos espaços por onde transitam os fluxos" (p. 26). É justo nesse embate que está sendo construído o futuro das comunicações, e, obviamente, afetando dramaticamente a educação.

Assim, o fechamento ou a abertura de alguns recursos que constituem cada camada da cadeia de produção de bens imateriais, limita ou aumenta a liberdade do processo de criação do professor e de seus alunos. 


\section{NA CAMADA FÍSICA: A CONECTIVIDADE}

A camada física, conforme Sérgio Amadeu da Silveira (2011), é administrada no mundo por um número limitado de grandes corporações de telecomunicações, as quais constituem um dos mais lucrativos segmentos econômicos oligopolizados da atualidade. Quanto mais cresce o uso das redes digitais, maior é o aumento do fluxo de informações que passam pelas redes físicas desses oligopólios, deixando-os com um grande poder sobre a infraestrutura de comunicação. $\mathrm{O}$ autor afirma que "diversos setores da sociedade passaram a enxergar o poder descomunal que este segmento adquiriu sobre o conjunto da comunicação digital. Quem controla a infraestrutura física da rede pode controlar o fluxo digital da rede" (SILVEIRA, 2011, p. 55-56).

O fluxo digital da rede pode ser visto por dois lados: a rede amplia a liberdade de expressão, expande a capacidade de interação entre as pessoas, entretanto, ela também é uma rede cibernética de comunicação e controle. Ao mesmo tempo que se constitui um repositório de informações jamais visto na história da humanidade, nunca fomos tão controlados. O "poder comunicacional", sustentado por Castells (2003), e comentado por Silveira (2011), é uma expressão que "pode ser empregada para definir o grau de autonomia que um indivíduo ou coletivo possui para obter informações e disseminar conteúdos, independente da vontade de outros indivíduos ou coletivos" (p. 52). Para o autor, no momento que deixa os sujeitos de algumas regiões do país sem conexão ou sem assegurar o direito das camadas mais pobres da sociedade ao uso da comunicação em redes digitais, “o Estado e seus grupos hegemônicos deixam milhares de pessoas sem a possibilidade de obter mais poder a partir do desenvolvimento da capacidade de criar redes, articulações e interações com vistas à defesa ou à ampliação de seus interesses”. (p. 53).

O Estado, por meio das políticas públicas, procura levar a tecnologia para todos os segmentos da sociedade, incluindo aí o importante segmento da educação, pela conexão das escolas. Para assegurar o acesso dos alunos das escolas públicas à internet, foi lançado pelo governo federal, em 4 de abril de 2008, pelo Decreto Presidencial n. ${ }^{\circ}$ 6.424, o Programa Banda Larga nas Escolas (PBLE) ${ }^{\mathrm{ii}}$, com o objetivo de conectar todas as escolas urbanas à internet até 2010. O governo fez um acordo com as operadoras de telefonia e com a Agência Nacional de Telecomunicações. No acordo, as teles deixaram de fornecer Postos de Serviços Telefônicos (PST) em cada cidade brasileira e passaram a distribuir seus backhauls ${ }^{\mathrm{iii}}$, em todos os municípios. Também ficou decidido que as teles deveriam oferecer acesso à internet gratuito para as escolas, atualizando periodicamente a velocidade até 2025.

Com base nas nossas experiências de atuação junto às escolas da Bahia, percebemos que as operadoras têm oferecido um serviço de baixa qualidade. A conexão existe, mas com muitos problemas, a exemplo da sua baixa velocidade, a não estabilidade da mesma, com frequente corte de serviço, falta de suporte, entre outros. A fragilidade do serviço oferecido denuncia uma falta de consistência nessa política pública. As operadoras, por serem empresas comerciais que visam negócios, não priorizam as escolas, pois essas não geram lucros. $\mathrm{O}$ acordo com o governo foi assinado em função das outras facilidades obtidas nas licitações, ficando o cumprimento das obrigações previstas nas metas de universalização e continuidade definidas na Lei Geral de Telecomunicações de 1997, como um serviço de baixa qualidade. Esses problemas trazem, como 
consequência, amarras que impossibilitam a apropriação das potencialidades da internet nas escolas para proposição de práticas autorais.

O Censo Escolar $2012^{\text {iv }}$, realizado pelo Inep, aponta que apenas 45,8\% das escolas de Ensino Fundamental do Brasil estão conectadas e a velocidade de conexão delas se concentra na faixa de 1 a 2 Mbps, não atendendo às demandas da realidade escolar. Assim, professores e alunos ficam impossibilitados de terem acesso aos diferentes ambientes da rede. Junto a essa dificuldade de acesso à internet nas escolas, há uma ausência de conexão nos domicílios das classes $\mathrm{C}, \mathrm{D}$ e $\mathrm{E}$, aos quais pertencem os alunos da rede pública de ensino, conforme apontado nos resultados da pesquisa do CGI. Br. ${ }^{\mathrm{v}}$

A forma como é implantada a infraestrutura de conectividade gera desigualdades de oportunidades no uso da rede. É perceptível que atualmente não basta conectar os cidadãos, sendo necessário conectá-los em velocidades compatíveis com o desenvolvimento das aplicações, sistemas e soluções na rede. Desconsiderar tal proposição, como afirma Silveira (2011), pode gerar políticas assimétricas, que consolidam o poder na rede e o poder de criar redes, daqueles que são mais velozes, que possuem mais capital ou mais poder político. Em certo sentido, a assimetria cria cidadãos conectados de categorias distintas no uso da rede. Portanto, conectar um local, por exemplo, uma escola, à internet "é um passo importante, mas se o acesso for em banda estreita, dificilmente aquela comunidade poderá acessar recursos tecnológicos que dependem de uma alta transferência de dados por segundo" (SILVEIRA, 2011, p.54).

Considerando as três leis da Cibercultura recombinante ${ }^{\mathrm{vi}}$, proposta por André Lemos (2005; 2009b), podemos afirmar que, na contemporaneidade, ter acesso ao conhecimento não é suficiente, é preciso também, e quem sabe, principalmente, produzi-lo. Para o autor (2009a), "não basta emitir sem conectar, compartilhar, é preciso emitir em rede, entrar em contato com outros, produzir sinergias, trocar pedaços de informação, circular, distribuir" (p. 40). Para nós é, ainda, transformar as informações recebidas e, ao remixá-las, produzir mais conhecimentos que precisam ser imediatamente socializados, instituindo-se "um círculo virtuoso de produção de culturas e conhecimentos" (PRETTO, 2012, p. 105). Para tal, necessário se faz termos professores e alunos conectados em velocidade compatível com os desejos e práticas de produção.

A recombinação cibercultural acontece a partir das modulações de informações que circulam na rede. Portanto, é preciso fazer download ou assistir vídeos, baixar áudios ou ouvi-los, tudo diretamente da internet, assim como fazer upload do material produzido. Uma banda larga de qualidade na escola permite que alunos e professores, para muito além de serem consumidores de informações, possam criar vídeos, áudios, textos, imagens, remixar qualquer tipo de conteúdo disponível, em diferentes linguagens. Preconizamos, dessa forma, a necessária vivência plena do universo da cultura digital, com uma imersão dos professores e alunos no universo de informação e comunicação propiciado pelas tecnologias digitais.

Superar os problemas referentes à infraestrutura tecnológica é fundamental para que possamos começar a pensar em outras possibilidades para a escola, deixando de lado a perspectiva dominante de recepção de informação para assumirem uma postura ativa, de produtores de culturas e 
conhecimentos.

\section{NA CAMADA LÓGICA: OS SOFTWARES E OS ARQUIVOS DIGITAIS}

A camada lógica compreende os padrões, protocolos e softwares, bem como os sistemas operacionais que são necessários para a interação entre o usuário e os dispositivos. Benkler (2007) afirma que nesse nível aparece "um ponto de controle sobre o fluxo e, portanto, sobre as oportunidades de produção e compartilhamento de informação e cultura". (p. 17). O autor enfatiza que, para construir uma base comum, deve haver uma política sistemática de preferência pelos padrões e protocolos abertos, em detrimento dos fechados; deve haver, principalmente, o incentivo ao uso do software livre, em detrimento do proprietário.

O movimento Software Livre foi criado, justamente, em prol do compartilhamento do conhecimento tecnológico. Mas, em oposição a esse movimento, há os que tentam aprisionar o conhecimento por interesses econômicos. Se, por um lado, temos os hackers ${ }^{\text {vii }}$ (acadêmicos, cientistas e algumas forças político-culturais) como os maiores defensores e apoiadores da distribuição mais igualitária dos benefícios da sociedade da informação, por outro lado, "há as megaempresas que vivem exclusivamente de um modelo econômico baseado na exploração de licenças de uso de software e do controle monopolístico dos códigos essenciais dos programas de computadores" (SILVEIRA, 2004, p. 6). Para o autor, a esse segundo grupo se alinham os governantes, frações burocráticas e políticos, além dos agentes pragmáticos interessados no financiamento que podem receber dos megagrupos que querem bloquear a disseminação dos conhecimentos básicos sobre o principal produto da sociedade em rede, o software.

A essência do software livre é a liberação do seu código-fonte e não apenas a comercialização da licença do seu código objeto ${ }^{\text {viii }}$, a característica principal do software proprietário. Os softwares livres, a depender da escolha dos autores, podem permitir: executar um programa para qualquer intento, irrestritamente; estudar um programa, e adaptá-lo às suas necessidades, modificando-o; redistribuir cópias e assim ajudar outros interessados; melhorar o programa e entregar tais melhorias para a comunidade, compartilhando as versões modificadas, gratuitamente ou não. Mas, para tal, devem ser registrados com os seus respectivos tipos de licenças. Uma das mais conhecidas é a GNU GPL (General Public Licence), uma licença que compõe o aparato legal acerca dos direitos autorais dos programas de computadores, desenvolvida pela Free Software Foundation ${ }^{\text {ix }}$.

Os softwares proprietários seguem o caminho inverso do software livre. O usuário não o compra, tem apenas a licença de uso do mesmo. O programa continua sendo de propriedade da empresa e/ou do autor. As licenças dos sistemas operacionais e aplicativos proprietários objetivam limitar a liberdade dos usuários de conhecer seu código-fonte, de copiá-lo, redistribuí-lo ou alterá-lo, conforme as necessidades de cada indivíduo ou de cada instituição.

Para Simon e Vieira (2007), as liberdades de usos do software livre trazem uma série de consequências econômicas, sociais e culturais. Uma delas é que diminuem os custos para o desenvolvimento. Sergio Amadeu da Silveira (2004) ressalta que a diferença entre os modelos de desenvolvimento do software livre e do proprietário fica mais evidente quando se observa o desenho e confecção dos programas. Todo o desenvolvimento do software proprietário é interno à_empresa, 
que contrata programadores assalariados e terceirizados. Já o software de código aberto segue um modelo colaborativo que envolve, além dos programadores da empresa, todos aqueles interessados no desenvolvimento do software, contando com voluntários espalhados pelo mundo. A maioria dos softwares livres é desenvolvida a partir das comunidades que se articulam por meio de sites, repositórios e listas de discussão, de forma a viabilizar que desenvolvedores possam trabalhar colaborativamente no seu desenvolvimento.

Assim, usar os programas e compreender os processos de produção e as formas de socialização de sistemas operacionais e outros tipos de programas são importantes ações para a formação do cidadão, especialmente porque envolvem processos que vão "além da dimensão técnica, implicando questões políticas, filosóficas, culturais e de gestão do conhecimento" (BONILLA, 2012, p.256). Ir além da dimensão técnica, significa que: em primeiro lugar, o software livre caracteriza-se como um movimento social, que se situa no plano político, por sua potencialidade para a democratização do acesso à tecnologia e ao conhecimento; em segundo, estamos diante de outro modelo de produção e socialização do conhecimento; em terceiro, ir além da dimensão técnica implica uma opção filosófica, porque envolve valores sociais, tais como direito à liberdade, à criação, à cooperação, à partilha de conhecimento, valores que compõem a chamada "ética hacker" (HIMANEN, 2004). Ou seja, implica construir uma nova cultura, socialmente mais justa, mais solidária, que oportunize articular redes de produção e socialização que permitam a todos usufruir dos bens imateriais produzidos pela humanidade.

Como o movimento do software livre está centrado no princípio de compartilhamento do conhecimento e na solidariedade praticada pela inteligência coletiva conectada em rede, é importante assegurarmos os direitos para o compartilhamento do conhecimento, contribuindo, assim, para a construção de uma sociedade livre, democrática e socialmente justa. Dessa forma, ao fortalecer a inteligência coletiva local, evita-se a sua submissão e aprisionamento pela inteligência monopolista e redutora das possibilidades de equalização social e de melhoria econômica dos povos (SILVEIRA, 2004). A troca permanente de informações e conhecimentos pode potencializar "a implantação de um círculo virtuoso de produção coletiva, inspirado na ideia de que conhecimento e cultura não são bens tangíveis e escassos, que ao serem consumidos se exaurem" (PRETTO, 2012, p. 2). Ao contrário, quanto mais eles circulam e são trocados, mais a criação é estimulada.

Entretanto, apesar de desde 2007, graças às políticas públicas de inclusão digital, os softwares livres virem sendo instalados nos computadores das escolas públicas e dos Núcleos de Tecnologia Educacional (NTE), ainda há muitos desafios a serem vencidos nesse contexto. Um deles é o entendimento de alguns docentes dos NTE e de gestores e professores das escolas sobre a importância da adoção de tais softwares e dos motivos que levaram o governo brasileiro a optar por essas soluções tecnológicas. O que temos constatado é que a maioria dos profissionais envolvidos com os projetos educacionais desconhece os princípios, as propriedades e as potencialidades desse movimento. Como consequência de tal situação, presenciamos, em algumas escolas que visitamos, a desinstalação do sistema operacional livre e de todos os demais programas que vêm instalados nos computadores, inclusive os ditos "educativos", e a substituição pelos sistemas proprietários. Esse desconhecimento fortalece a lógica monopolista e priva a comunidade escolar de explorar e conhecer as potencialidades dos sistemas abertos. 
Ainda na camada lógica, se encontra a tensão entre os formatos abertos e fechados. A comunicação por meios digitais são dependentes de formatos, que é o modo de codificação da informação para o seu armazenamento e recuperação em um arquivo de computador. Esses formatos são implementados por softwares que podem ser fechados (proprietários), ou seja, "o código que contém as instruções para o computador salvar e recuperar as informações não é acessível a todos" (SILVEIRA, 2012, p. 112). Sendo aberto (não proprietário) o formato, sua codificação não fica submetida a bloqueios legais de uso. Segundo o autor, os formatos são instrumentos de poder, pois há situações em que os mesmos condicionam e, inclusive, determinam nossa comunicação. Ressalta que algumas corporações de tecnologia, com seus interesses comerciais, controlam os formatos, os padrões de uso, monopolizando e aprisionando os usuários em seus softwares.

Os formatos abertos de documentos digitais garantem a interoperabilidade ${ }^{\mathrm{x}} \mathrm{e}$ a compatibilidade de documentos produzidos a partir de softwares diferentes, a exemplo do Open Document Format (odf), que pode ser aplicado por toda e qualquer suíte de escritório (textos, planilhas, apresentações, desenhos).

\section{NA CAMADA DE CONTEÚdO: AS NORMAS PARA USOS DO CONHECIMENTO}

Na camada do conteúdo estão as condições para novas criações e também os processos de controle dos ditos proprietários dos produtos culturais que determinam quem fala o que e para quem. Também estão os conflitos em torno da propriedade intelectual e dos modelos de negócio que dependem de um controle rígido sobre a informação e a cultura existentes (BENKLER, 2007, p. 17). Assim, é em torno dessas questões que vem se desenvolvendo "toda uma campanha de combate à chamada pirataria, capitaneada pela indústria cultural, que se sente ameaçada pelas novas formas de produção e circulação dos bens culturais proporcionados pelas tecnologias digitais" (BONILLA, 2012, p. 264). Por outro lado, têm se intensificado cada vez mais na sociedade brasileira, movimentos contrários a essas tentativas de coerção, entre eles, destacamos a reforma da Lei de Direitos Autorais (Lei n. ${ }^{\circ}$ 9.610/98) e a incorporação de outros tipos de licenças, mais abertas, que oferecem mais liberdade para as criações.

Apesar de nossas pesquisas não estarem vinculadas ao campo do Direito, um dos motivos para contemplar essa discussão sobre direitos autorais origina-se das questões relacionadas aos direitos de acesso e de apropriação que giram em torno dos "produtos" culturais no processo criativo de professores e alunos no cotidiano da escola e da universidade. A todo momento utilizamos - nas aulas - vídeos, áudios, músicas, desenhos, textos, disponibilizamos links nos ambientes virtuais para estudos, solicitamos releituras de obras artísticas, promovemos remixagens de materiais já produzidos, entre tantos outros diferentes usos que fazemos dos objetos culturais disponíveis na sociedade, seja em ambientes presenciais ou não presenciais.

Temos, nos dias de hoje, uma enorme disponibilidade de ambiências de informação e comunicação que permitem a coautoria, com práticas culturais de construção de conhecimentos na adaptação, edição, retransmissão de conteúdo, que são denominadas de práticas de remix ciberculturais, e que queremos incentivar nas instituições educacionais. No entanto, todos esses 
movimentos são ilegais, visto que, de acordo com o Artigo 33 da Lei de Direitos Autorais ${ }^{\mathrm{xi}}$, "ninguém pode reproduzir obra que não pertença ao domínio público, a pretexto de anotá-la, comentá-la ou melhorá-la, sem permissão do autor".

Essa Lei do Direito Autoral regulamenta a produção textual literária, acadêmica e jornalística e, também, toda a criação fonográfica e audiovisual, programas de computador e tudo mais que envolva processos de criação e desenvolvimento, sendo a indústria cultural quem mais se beneficia com ela. Até um passado bem recente, com a necessidade imperiosa de intermediários para se fazer chegar à população as criações, o autor cedia todos os seus direitos para as gravadoras, as emissoras de televisão e rádio, produtoras cinematográficas, editoras, entre outros, ficando na dependência das permissões e limitações mercadológicas, e sem autonomia para fazer o que desejar com sua própria criação.

O que se verifica atualmente, conforme Marcos Wachowicz e Carol Proner (2012), é que a sociedade está vivenciando uma verdadeira disputa de interesses econômicos, uma vez que esses intermediários passam a ser os donos do conteúdo digital das obras e, para protegerem os seus modelos de negócios, lutam, em todas as esferas, para ampliar as restrições de acesso, via políticas de "proteção" de direitos autorais. Dificulta-se, com isso, o acesso à informação, à educação, à cultura e ao conhecimento. $\mathrm{O}$ desafio posto

[...] reside em combinar a legítima proteção aos autores (inclusive no que concerne à melhor remuneração destes), e as inúmeras oportunidades de convergência tecnológicas, que favorecem o sistema nacional de propriedade intelectual moderna, promovendo assim uma sociedade menos desigual no acesso à cultura e ao conhecimento. (WACHOWICZ; PRONER, 2012, p. 26)

Os consumidores, conforme enfatiza Rafael Biihrer (2010), por não possuírem nenhum direito sobre a obra, não podem utilizá-la, já que para qualquer que seja o uso, como editar, retransmitir, fazer circular, necessitam de uma permissão das empresas intermediárias, muito mais do que do próprio autor da obra. Não se apregoa aqui a não garantia dos direitos associados à autoria, mas, sim, a liberdade de uso dos conhecimentos socialmente produzidos. O que está em questão é a inadequação da legislação atual, considerando os avanços tecnológicos, principalmente os trazidos pela digitalização das informações.

Como aponta Lawrence Lessig (2005), esse sistema amputa a criatividade e a inovação, uma vez que, como Biihrer (2010) constata, o mesmo foge da lógica da criação amadora, além de que, o trabalho envolvido para a solicitação da licença e o alto custo dos serviços acarreta o impedimento da geração de novos conteúdos; ou então, leva à violação dos direitos autorais, "ocasionando assim um pessimismo generalizado com relação ao desafio da internet” (GANDELMAN, 2004, p.127).

Diante desse cenário, estudos e debates vêm sendo realizados em torno de questões relacionadas a mudanças da lei de direitos autorais. Entre eles, podemos destacar algumas das publicações do Grupo de Estudos de Direito Autoral e Informação - GEDAI da Universidade Federal de Santa Catarina (WACHOWICZ e SANTOS, 2010; WACHOWICZ, 2011; WACHOWICZ e PIONER, 2012). 
Ao ser elaborada a legislação em vigor, os legisladores da época não puderam incorporar, por não existirem, as especificidades do mundo digital, que alteraram, de forma radical, as maneiras de se expressar, os modos de criação e, ainda, a significativa diminuição dos custos de produção e reprodução, alterando, obviamente, os modelos de negócios instituídos até então. Segundo Wachowicz (2010), no novo cenário que se delineou no século XXI, foram surgindo os desequilíbrios nas relações entre os autores/criadores e os investidores, visto que é dada total cessão dos direitos a estes, sem possibilidade de revisão do contrato.

Carlos Gerbase (2008) ressalta que o debate legal e jurídico nunca aconteceu separado de forças pragmáticas, cotidianas que atuam em pelo menos três níveis. O primeiro deles diz respeito ao jogo político e econômico que envolve os poderes Executivo e Legislativo, em especial nas negociações eleitorais; o segundo é a articulação dos discursos da mídia (com destaque para a televisão), sempre que as grandes empresas - hegemônicas - se sentem ameaçadas com alguma regulamentação que julgam nociva aos seus interesses; o terceiro é o que acontece no campo das práticas do Direito, que se transformam em práticas de coerção, executadas ao abrigo da lei, mesmo que sejam arbitrárias e imorais. Para o autor, essas práticas "são criadoras de um 'regime de verdade', que vai se impondo e contemplando os interesses da indústria do audiovisual, mesmo que tenham sua origem em supostos interesses dos autores, que não passam de coadjuvantes" (GERBASE, 2008, p.151). Dessa forma, é preciso que "se alcance um equilíbrio entre os interesses públicos e privados. Os primeiros relativos ao acesso ao conhecimento e à cultura, e os segundos, relativos aos aspectos econômicos de exploração e comercialização" (WACHOWICZ, 2010, p. 79). Obviamente, esse equilíbrio só ocorrerá com uma revisão dos paradigmas do direito autoral frente ao direito cultural.

Pesquisadores do campo do direito autoral, como Wachowicz (2010) e Santos (2010), entre outros, afirmam que a estrutura central da Lei n. ${ }^{\circ}$ 9.610/98 continua válida, porém é inadequada ou insuficiente para regular os direitos autorais diante do cenário das tecnologias digitais. Para Manoel dos Santos, "as obras clássicas devem ter um tratamento distinto das obras digitais e das criações dirigidas", e, "indubitavelmente, o sistema tradicional não é adequado para as bases de dados, software e agora websites" (p. 56). Para Henrique Gandelman (2004), o "ciberespaço modifica certos conceitos de propriedade, principalmente intelectual - atingindo também princípios éticos e morais tradicionais -, o que vem dando origem a uma nova cultura, [identificada como a que permite a] liberdade de informação" (p.128).

No Brasil, um longo processo de revisão da legislação foi iniciado e, até hoje, agosto de 2015, não foi concluído, o que demonstra a complexidade do tema e, principalmente, o poderio das grandes corporações interessadas na temática. Em paralelo à luta pela urgente reformulação da legislação sobre o direito autoral, cresce o movimento social em torno da cultura livre. Vários projetos de "licenças públicas e criações colaborativas vêm sendo implementados, o que tem como principal resultado o aumento do domínio público - espontâneo, não legal - e, consequentemente, a possibilidade de uso de obras alheias" (PARANAGUÁ; BRANCO, 2009, p. 109). O tema do licenciamento dos produtos culturais e científicos é importante como uma forma de proteger aqueles autores que têm como princípio o compartilhamento de suas produções. Destacamos neste artigo dois tipos de licenciamento de uma obra, o Copyleft e o Creative Commons. 
O Copyleft ${ }^{x i i}$ nasce no mundo dos programas de computadores, é um trocadilho com o termo Copyright e significa permitida a cópia. Ele vem sendo utilizado por diversas instituições em diferentes campos, por empresas e indivíduos que querem compartilhar suas obras e permitir que seja utilizada por outras pessoas. Os termos do Copyleft "garantem o reconhecimento do autor, mas permitem que qualquer pessoa possa intervir, alterando, reproduzindo, redistribuindo e, por fim, [se desejar] revendendo esse produto" (VALOIS, 2003, p. 294). Esse formato dispensa os intermediários. A única restrição é que ninguém se aposse, sinta-se proprietário do produto ou do conhecimento gerado, independentemente de sua parcela de contribuição na criação. Dessa forma, mesmo sem autorização expressa dos titulares de seus direitos autorais, não há risco de processos judiciais.

Caminhando do Copyleft em direção ao tradicional Direito Autoral, encontram-se as licenças Creative Commons $(C C)^{x i i i}$, um conjunto gratuito de licenças que podem ser anexadas ao conteúdo criado. Esse conjunto de licenças foram idealizadas pelo jurista Lawrence Lessig (2005), que as criou com o objetivo de alargar a quantidade de obras criativas, e foram elaboradas rigorosamente centradas na legislação de direito autoral, não pretendendo executar ações ofensivas sobre o copyright, mas construir uma camada mais razoável sobre os direitos de autor, desafiando os extremos prevalecentes na lei atual. As licenças Creative Commons buscam simplificar os processos de licenciamento do conhecimento produzido pela humanidade, de tal modo que, na criação, seja possível utilizar obras alheias, com os devidos registros, tudo isso facilitado pelo sistema de licenciamento disponibilizado online na internet e, dessa forma, dispensando-se os intermediários e os advogados (LESSIG, 2005, p. 275). Como as versões da licença são legíveis eletronicamente, permitem que os computadores possam identificar de maneira automática o conteúdo cujo compartilhamento foi facilitado por seus autores, com as liberdades asseguradas a partir da escolha de seus criadores, por meio dos diversos tipos de licenças disponíveis.

Essa abertura contribui para o acesso ao saber e ao conhecimento, e o aumento da produção de conteúdos, uma vez que, a partir do digital e com intensivo uso das redes informacionais, não precisamos pensar na escassez desses conteúdos, uma vez que o compartilhamento de um bem intelectual não implica na sua perda. Assim sendo, a informação pode ser partilhada inúmeras vezes para diferentes pessoas, implantando-se o que denominamos de "um círculo virtuoso de produção de culturas e conhecimento". (PRETTO, 2012, p. 105). Ou seja, "a proposta de adoção da Creative Commons (produção colaborativa) evolui para a constituição de uma verdadeira economia das redes de informação baseada na colaboração" (WACHOWICZ; PRONER, 2012, p. 25).

Entendemos que essas possibilidades contribuem para que a criatividade seja disseminada com mais facilidade na sociedade, mas, principalmente, que sejam aproveitadas em ações criativas no cotidiano da escola, ampliando o patrimônio cultural, consequentemente disseminando cultura e conhecimento. Isso porque pensamos que só é possível investir em uma educação baseada na criação, na participação e no compartilhamento, se houverem profundas "transformações na legislação sobre o direito autoral [e] um olhar mais atento para os movimentos em torno do acesso aberto ao conhecimento" (PRETTO, 2012, p. 95). Cabe ressaltar que toda obra não pode apenas ter intenção de ser livre, tem que carregar formalmente essas licenças, pois elas garantem aos praticantes liberdades para se apropriarem e remixarem, usá-las de acordo as suas necessidades. 


\section{CONSIDERAÇÕES FINAIS}

Construir uma infraestrutura tecnológica básica comum é "precondição necessária para nos permitir sair de uma sociedade de consumidores passivos que compra o que é vendido por um pequeno grupo de produtores comerciais. É o que vai nos permitir desenvolver uma sociedade em que todos tenham o direito de falar a todos", afirma Benkler (2007, p. 20). Nesse cenário, qualquer um pode usar os meios, interagir, efetuar trocas, participar dos processos de produção de cultura e conhecimento, enfim, se tornar participante ativo do discurso político, econômico, social e cultural. A cultura, a arte de modo geral, e a ciência se auto alimentam e isso significa que as criações sempre derivam do conhecimento humano disponível.

Quanto mais se impossibilita a utilização desse conhecimento, mediante restrições legais, menor a quantidade de matéria-prima disponível para novas criações e, com isso, diminuem as possibilidades de produções coletivas e colaborativas de conhecimentos em rede. Diminuem também as possibilidades de autoria, especialmente no contexto educacional. Autoria na educação é entendida como a disponibilidade e a ação destinadas à produção, criação, crítica, expressão e iniciativa para a proposição de práticas pedagógicas inovadoras. A perspectiva supera unicamente o consumo do disponível na rede e se alicerça na compreensão dos objetos para adequá-los às diferentes realidades, apropriando-se deles de modo singular, com isso, extrapolando os padrões de consumo idealizados pelos produtores dos bens culturais e dos materiais educacionais, e possibilitando a criação de metodologias e conteúdos pedagógicos próprios de cada contexto escolar.

A autoria emerge dos interesses e das intencionalidades, das remixagens, das bricolagens ${ }^{\mathrm{xiv}}$, das escolhas, das produções individuais e coletivas, seja pelas modificações no aspecto estético e/ou estrutural, seja pelas transformações na forma e conteúdo, deixando professores e alunos de serem exclusivamente usuários para desbravar trilhas e formular proposições, de acordo com o contexto e as ocasiões que lhe são próprias. Nas escolas, a autoria só poderá ser materializada se for permitido a todos o direito e a liberdade de usufruir dos bens imateriais produzidos pela humanidade, bases necessárias para oportunizar a constituição de cidadãos que saibam pensar e intervir, fazer escolhas, tomar decisões.

\section{REFERÊNCIAS}

BENKLER, Yochai. A economia política dos commons. In: SILVEIRA, Sérgio Amadeu da; BENKLER, Yochai; WERBACH, Kevin; BRANT, João; GINDRE, Gustavo (Org.). Comunicação digital e a construção dos commons: redes virais espectro aberto e as novas possibilidades de regulação. São Paulo: Perseu Abramo, 2007. p.11-20.

BONILLA, Maria Helena Silveira. Software livre e formação de professores: para além da dimensão técnica. In: FANTIN, Monica; RIVOLTELLA, Pier Cesare (Org.). Cultura digital e escola: pesquisa e formação de professores. Campinas: Papirus, 2012. p. 253-281.

BIIHRER, Rafael Arrais. A cultura do remix: hibridismo e cibercultura. 2010. Trabalho de Conclusão de Curso (Bacharelado em Comunicação Social - Habilitação em Publicidade e Propaganda). Escola de Comunicações e Artes, Universidade de São Paulo, São Paulo, SP, 2010. 
CASTELLS, Manoel. A galáxia da internet: reflexões sobre a internet, os negócios e a sociedade. Rio de Janeiro: Zahar, 2003.

GANDELMAN, Henrique. O que você precisa saber sobre direitos autorais. Rio de Janeiro: Senac Nacional, 2004.

GERBASE, Carlos. A fabricação da verdade no debate sobre direitos autorais no Brasil. In: PRETO, Nelson de Luca; SILVEIRA, Sérgio Amadeu da (Org.). Além das redes de colaboração: internet, diversidade cultural e tecnologias do poder. Salvador: EdUFBA, 2008. p. 133-153. Disponível em: < http://goo.gl/iqmeua>. Acesso em: 01 out. 2013.

HIMANEN, Pekka. Etica del hacker y el espiritu de la era de la informacción. Barcelona: Destino, 2004.

LAPASSADE, Georges. Da multirreferencialidade como "bricolagem”. In: BARBOSA, Joaquim Gonçalves (Coord.). Multirreferencialidade nas ciências e na educação. São Carlos: EdUFSCar, 1998. p. 126-148.

LEMOS, André. Ciber-cultura-remix. Apresentado ao Seminário "Sentidos e Processos" dentro da mostra Cinético Digital, no Centro Itaú Cultural. São Paulo: Itaú Cultural. ago. 2005. Disponível em: <http://goo.gl/UW7eMR>. Acesso em: 24 abr. 2010.

LEMOS, André. Cibercultura como território recombinante. In: TRIVINHO, Eugênio; CAZELOTO, Edilson (Org.) A cibercultura e seu espelho [recurso eletrônico]: campo de conhecimento emergente e nova vivência humana na era da imersão interativa, São Paulo: ABCiber, 2009a. p. 3846.

LEMOS, André. Arte e mídia locativa no Brasil. In: LEMOS, André; JOSGRILBEG, Fabio (Org.). Comunicação e mobilidade: aspectos socioculturais das tecnologias móveis de comunicação no Brasil. Salvador: EdUFBA, 2009b. p. 89-108.

LEMOS, André; LÉVY, Pierre. O futuro da internet: em direção a uma ciberdemocracia planetária. São Paulo: Paulus, 2010.

LESSIG, Lawrence. Cultura livre: como a grande mídia usa a tecnologia e a lei para bloquear a cultura e controlar a criatividade. São Paulo: Trama, 2005. Disponível em:

<http://goo.gl/ImQ2xv>. Acesso em: 13 ago. 2013.

LÉVY, Pierre. A inteligência coletiva: por uma antropologia do ciberespaço. 4. ed. São Paulo: Loyola, 2003.

MARTINS, Beatriz Cintia. Autoria em rede: um estudo dos processos autorais interativos de escrita nas redes de comunicação. 2012. 155 f. Tese (Doutorado em Ciências da Comunicação) - Escola de Comunicações e Artes, Universidade de São Paulo, São Paulo, SP, 2012. Disponível em: <https://goo.gl/YPRT02>. Acesso em: 01 out. 2013.

PARANAGUÁ, Pedro; BRANCO, Sérgio. Direitos autorais. Rio de Janeiro: Editora FGV, 2009.

PRETTO, Nelson de Luca. Professores-autores em rede. In: SANTANA, Bianca; ROSSINI,

Carolina; PRETTO, Nelson de Luca (Org.). Recursos educacionais abertos: práticas colaborativas,

\begin{tabular}{l|l|l|l|l|l|l} 
(C) ETD - Educ. Temat. Digit. & Campinas, SP & v.18 & n.1 & p. 43-59 & jan./abr. 2016 & ISSN 1676-2592
\end{tabular}


e políticas públicas. Salvador: EdUFBA; São Paulo: Casa de Cultura Digital, 2012. Disponível em: <http://goo.gl/9zMpj2>. Acesso em: 13 set. 2013.

SANTOS, Manoel Joaquim Pereira dos. Principais tópicos para a revisão da lei de direitos autorais. In: WACHOWICZ, Marcos; SANTOS, Manoel Joaquim Pereira dos (Org.). Estudos de direito de autor: a revisão da lei de direitos autorais. Florianópolis: Fundação Boiteux, 2010. p. 55-72. Disponível em: < http://goo.gl/ycpjZH>. Acesso em 01 out. 2013.

SILVEIRA, Sérgio Amadeu da. Software livre: a luta pela liberdade do conhecimento. São Paulo: Perseu Abramo, 2004.

SILVEIRA, Sérgio Amadeu. Redes virais e espectro aberto: descentralização e desconcentração do poder comunicacional. In: SILVEIRA, Sérgio Amadeu et al. Comunicação digital e a construção dos commons: redes virais, espectro aberto e as novas possibilidades de regulação. São Paulo: Perseu Abramo, 2007. p. 21-55.

SILVEIRA, Sérgio Amadeu. Para além da inclusão digital: poder comunicacional e novas assimetrias. In: PRETTO, Nelson de Luca; BONILLA, Maria Helena Silveira (Org.). Inclusão digital: polêmica contemporânea. Salvador: EdUFBA, 2011. p.49-59.

SILVEIRA, Sérgio Amadeu da. Formatos abertos. In: SANTANA, Bianca; ROSSINI, Carolina; PRETTO, Nelson de Luca. Recursos educacionais abertos: práticas colaborativas e políticas públicas. Salvador: EdUFBA; São Paulo: Casa da Cultura Digital, 2012. Disponível em: <http://goo.gl/lFHFHQ>. Acesso em: 11 ago. 2015.

SIMON, Imre; VIEIRA, Miguel Said. A propriedade intelectual diante da emergência da produção social. Social Science Research Network. 2007. Disponível em:

<http://goo.gl/yiS0IK>. Acesso em: 01 out. 2013. ISSN 0049-089X.

SIMON, Imre; VIEIRA, Miguel Said. O rossio não rival. In: PRETTO, Nelson de Luca; SILVEIRA, Sérgio Amadeu da. Além das redes de colaboração: internet, diversidade cultural e tecnologias do poder. Salvador: EdUFBA, 2008. p. 15-30.

WACHOWICZ, Marcos; SANTOS, Manoel Joaquim Pereira dos (Org.). Estudos de direito de Autor: a revisão da lei de direitos autorais. Florianópolis: Boiteux, 2010. p.73-101.

WACHOWICZ, Marcos; PRONER, Carol (Org.). Movimentos rumo a sociedade democrática do conhecimento. In: WACHOWICZ, Marcos; PRONER, Carol (Org.). Inclusão tecnológica e direito a cultura: movimentos rumos à sociedade democrática do conhecimento. Florianópolis: Boiteux, 2012. p. 15-38. Disponível em:

< http://goo.gl/Rf8daA $>$. Acesso em: 11 ago. 2015.

WACHOWICZ, Marcos (Org.). Por que mudar a lei de direito autoral? Estudos e pareceres. Florianópolis: Editora FUNJAB, 2011. Disponível em: < http://goo.gl/lLGzx4>. Acesso em: 11 ago. 2015.

VALOIS, Djalma. Copyleft. In: SILVEIRA, Sérgio Amadeu; Cassino, João (Org.). Software livre e inclusão digital. São Paulo: Conrad do Brasil, 2003. p.287-317. 


\section{NOTAS}

\footnotetext{
${ }^{\text {i }}$ Para Benkler, "Propriedade é um conjunto de regras que determinam: qual recurso cada um de nós tem ao estabelecer uma relação com outros; o que a 'posse' ou 'falta' de um recurso nos permite fazer ou recusar a fazer nas relações em torno destes recursos. Essas regras impõem restrições sobre quem pode fazer o que no domínio das ações que exigem acesso aos recursos sujeitos às leis da propriedade" (BENKLER, 2007, p.12).

${ }^{i i}$ Disponível em: http://portal.mec.gov.br/index.php?option=com_content\&view=article\&id=15808:programa-bandalarga-nas-escolas\&catid=19..> Acesso em 25 out 2013.
}

iii Segundo a Wikipédia, "Backhaul é a porção de uma rede hierárquica de telecomunicações responsável por fazer a ligação entre o núcleo da rede, ou backbone, e as sub-redes periféricas. Por exemplo, em uma rede de telefonia celular, enquanto uma única torre de célula constitui a sub-rede local, a conexão dessa torre ao restante do mundo é feita por um link backhaul ao núcleo da rede da companhia telefônica". Disponível em: <http://pt.wikipedia.org/wiki/Backhaul> iv Disponível em:

<http://download.inep.gov.br/educacao_basica/censo_escolar/resumos tecnicos/resumo tecnico_censo_educacao basica 2012.pdf > Acesso em $08 \mathrm{dez} 2013$.

${ }^{v}$ http://www.cetic.br/publicacoes/2012/tic-domicilios-2012.pdf

vi A primeira lei emerge da liberação da palavra em redes telemáticas e é a da conexão e da conversação mundial (LEMOS e LÉVY, 2010) ou da inteligência coletiva (LÉVY, 2003); a segunda, é a da conectividade generalizada; a terceira, é a da reconfiguração social.

vii Podem-se definir os hackers não como a mídia vem apontando-os, pois eles não são irresponsáveis, não buscam quebrar os códigos, nem penetrar em sistemas ilegalmente ou criar conflitos no tráfego dos computadores. Os que têm esse comportamento são denominados de crackers e seus atos de vandalismos são abominados pelos hackers. Os hackers são aqueles indivíduos que se dedicam com entusiasmo, passando horas de seu tempo com a atividade de programação, que acreditam que o compartilhamento de informações é um bem poderoso e positivo, e que é dever ético dos hackers compartilhar experiências elaborando softwares gratuitos e facilitar o acesso a informações e a recursos de computação sempre que possível.

viii "Em programação de computadores, código objeto ou arquivo objeto é o nome dado ao código resultante da compilação do código fonte. Normalmente, o código fonte é formado por uma sequência de instruções no formato especificado por alguma linguagem de programação. Para cada arquivo de código fonte é gerado um arquivo com código objeto, que posteriormente é 'ligado' aos outros, através de um linker, resultando num arquivo executável ou biblioteca." Fonte: <http://pt.wikipedia.org/wiki/C\%C3\%B3digo_objeto>

ix “A Free Software Foundation (FSF, Fundação para o Software Livre) é uma organização sem fins lucrativos, fundada em 04 de Outubro de 1985 por Richard Stallman e que se dedica à eliminação de restrições sobre a cópia, redistribuição, estudo e modificação de programas de computadores - bandeiras do movimento do software livre, em essência. Faz isso promovendo o desenvolvimento e o uso de software livre em todas as áreas da computação mas, particularmente, ajudando a desenvolver o sistema operacional GNU e suas ferramentas". Fonte: <

http://pt.wikipedia.org/wiki/Free_Software_Foundation>

${ }^{x}$ Interoperabilidade é a capacidade de um sistema (informatizado ou não) de se comunicar de forma transparente (ou o mais próximo disso) com outro sistema (semelhante ou não). Para um sistema ser considerado interoperável, é muito importante que ele trabalhe com padrões abertos. Fonte: 〈http://pt.wikipedia.org/wiki/Interoperabilidade〉.

${ }^{x i}$ Lei dos Direitos Autorais. Disponível em: <http://www.planalto.gov.br/ccivil_03/leis/19610.htm> Acesso em 01 out de 2013.

xii “Copyleft é uma forma de usar a legislação de proteção dos direitos autorais com o objetivo de retirar barreiras à utilização, difusão e modificação de uma obra criativa devido à aplicação clássica das normas de propriedade intelectual, exigindo que as mesmas liberdades sejam preservadas em versões modificadas. Ele difere assim do domínio público, que 
não apresenta tais exigências; enquanto o domínio público permite qualquer utilização de uma obra, o copyleft, tem, via de regra, a única exigência de se poder copiar e distribuir uma obra. O copyleft também não proíbe a venda da obra pelo autor, mas implica a liberdade de qualquer pessoa fazer a distribuição não comercial da obra". Informação disponível em: <http://pt.wikipedia.org/wiki/Copyleft>Acesso em 26 set 2013.

xiii Fonte: www.creativecommons.org.br

${ }^{\text {xiv }}$ Bricolagem aqui entendida a partir do conceito de Claude Lévi-Straus, citado por Lapassade (1998, p.126), quando afirma que "[...] a regra desse jogo é sempre a de se ajeitar com recursos secundários, quer dizer, um conjunto sempre finito de ferramentas e de materiais heteróclitos".

\section{Como citar este documento:}

VELOSO, Maristela Midlej Silva de Araujo; BONILLA, Maria Helena Silveira; PRETTO, Nelson De Luca. A cultura da liberdade de criação e o cerceamento tecnológico e normativo: potencialidades para a autoria na educação. ETD Educação Temática Digital, Campinas, SP, v. 18, n. 1, p. 43-59, abr. 2016. ISSN 1676-2592. Disponível em: <http://periodicos.sbu.unicamp.br/ojs/index.php/etd/article/view/8639486>. Acesso em: 05 abr. 2016. doi: 〈http://dx.doi.org/10.20396/etd.v18i1.8639486>. 